\title{
An Optimal Identification of Clock Behaviour Model for VLBI
}

\author{
Dawei Zheng and Shifang Luo \\ Shanghai Observatory, Academia Sinica \\ J.R.Mackay \\ National Geodetic Survey Division \\ Charting and Geodetic Survices \\ National Ocean Service
}

\section{Introduction}

The accuracy of VLBI measument has reached centimeters(Carter et a1.,1985). But in VLBI observation the observable are broken sometimes because of the variations of the clock phases or frequencies. This is the first problem met in VLBI data processing.

Recently, the interactive mode is adopted to determine the intant of the clock discontinuities and the clock behaviour model of the seperate sections. By using this mode the results will not only be effected by personal cause (Robertson,1975), but also it takes a lot of computer time.

In this paper, we will discuss the estimates of clock models and the discontinuities in VLBI data processing by information criteria in order to improve the results and the procedure of VLBI data processing.

\section{The Optimal Estimate Method of Clock Behaviour Mode1}

According the physical character of atomic clock, the clock behaviour model in one session of VLBI can be described as

$$
O C t=\sum_{j=1}^{L}\left(a_{j}+b_{j} t+c_{j} t^{2}\right)+\varepsilon_{t}^{j}
$$

where $t$ is the argument of time, $\varepsilon_{t}^{j}$ is the noise in clock. When $L=1$, it means that the clock has no discontinuities in this session and only one clock behaviour model is needed. If $L \geqslant 2$, the clock has some variations and two or more models are needed to describe the clock behaviour in this session.

Then the followed Information Criteria presented by Akaike (1973) is adopted:

$\operatorname{AIC}(\hat{B}, \hat{T}, \hat{K})=\min \sum_{j=1}^{L}\left(N j^{\prime} \operatorname{Ln}\left(\operatorname{RSS}(K j) / N j^{\prime}\right)+2(K j+1)\right) \quad L=1,2, \ldots, L m$

$\hat{B}, \hat{T}$ and $\hat{\mathrm{K}}$ are the optimal estimates for the number, the instant of the clock discontinuities and for the orders of clock behaviour model respectively. Where $\mathrm{Lm}$ is the maximum number of clock behaviour model existed possiblly in the observations. RSS is the sum of the residural square after fitting $j$ th model and $\mathrm{Nj}^{\prime}$ is the freedom for $\mathrm{j}^{\text {th }}$ model. 
From the formula (2), the optimal estimates of $B, T$ and $K$ must simultaneously satisfy the condition of minimum of AIC.

\section{The Results}

In addition to the simulated data, the observations data of single baseline in POLARIS project in 1983 are also selected to estimate the $B, T$ and $K$, then to compute the site coordinates. The estimates of clock bahaviour models are listed in Table 1 and Table 2 with that ones obtained by manual mode in NGS. The results for the code of $0 \mathrm{C} 137$ and $\mathrm{OC} 144$ are shown in Fig. 1.

Table 1. the Estimates of Clock Behaviour Models by AIC and Manual

\begin{tabular}{|c|c|c|c|c|c|c|c|c|c|c|c|c|c|c|c|}
\hline \multirow{3}{*}{ Code } & & & & \multicolumn{5}{|c|}{ AIC } & \multicolumn{7}{|c|}{ Manua 1} \\
\hline & \multicolumn{3}{|c|}{ Date } & 1 & $\mathrm{k} 2$ & & $\begin{array}{r}\text { ista } \\
\text { di }\end{array}$ & $\begin{array}{l}\text { ant } \\
\text { isc. }\end{array}$ & MS & $\mathrm{k} 1$ & $\mathrm{k} 2$ & & $\begin{array}{l}\text { nsta } \\
\text { f di }\end{array}$ & & RMS \\
\hline & & y & d & & & & & $\mathrm{m}$ & ns & & & & & h & \\
\hline & 1983 & 8 & 1 & 1 & 2 & 2 & 1 & 24 & \pm .511 & 2 & 2 & 2 & 6 & 20 & t. 5 \\
\hline 1 & & 10 & 22 & 2 & 2 & 23 & 10 & 16 & & 1 & 2 & 23 & 10 & 20 & .3 \\
\hline 14 & & 11 & 26 & 2 & 1 & 27 & 10 & 1 & .2 & 2 & 2 & 27 & 6 & 0 & .2 \\
\hline 14 & & 12 & 6 & 2 & 1 & 7 & 5 & 42 & .28 & 2 & 2 & 7 & 6 & 15 & .2 \\
\hline 47 & & 12 & 11 & 2 & 1 & 12 & 8 & 56 & .296 & 2 & & 12 & & 15 & \\
\hline
\end{tabular}

Table 2. Differences of the Site Coordinates caused by Estimates of the Clock Behaviour Models with AIC and Manual

$\begin{array}{cccc}\text { Code } & \mathrm{X} & \mathrm{Y} & \mathrm{Z} \\ & (\mathrm{m}) & (\mathrm{m}) & (\mathrm{m}) \\ \text { OC122 } & -0.0144 & 0.1043 & -0.0831 \\ \text { OC137 } & -0.0013 & -0.0265 & 0.0291 \\ \text { OC144 } & -0.0031 & -0.0074 & 0.0082 \\ \text { OC146 } & -0.0030 & -0.0372 & 0.0312 \\ \text { OC147 } & -0.0011 & -0.0050 & -0.0024\end{array}$

The numbers of discontinuities obtained by AIC and Manual are compared as shown in Table 3 .

Table 3. the Effects on Site Coordinates from the Numbers of Clock Discontinuity Estimated by AIC and Manual

\begin{tabular}{|c|c|c|c|c|c|c|}
\hline Code & Date & number & of clock disc. & $\mathrm{DX}$ & $\begin{array}{l}\text { DY } \\
(\mathrm{m})\end{array}$ & $\begin{array}{c}\mathrm{DZ} \\
(\mathrm{m})\end{array}$ \\
\hline OC104 1983 & $\begin{array}{l}y \\
3 \quad 28\end{array}$ & $\begin{array}{c}\text { AIC } \\
1\end{array}$ & $\begin{array}{c}\text { Manual } \\
2\end{array}$ & $\begin{array}{c}(\mathrm{m}) \\
0.0019\end{array}$ & $\begin{array}{l}\text { (m) } \\
0.0320\end{array}$ & -0.0390 \\
\hline OC113 & 531 & 1 & 2 & 0.0209 & -0.2380 & 0.2064 \\
\hline OC119 & 711 & 0 & 2 & -0.0058 & -0.0433 & 0.0433 \\
\hline OC130 & $\begin{array}{ll}9 & 17\end{array}$ & 1 & 0 & 0.0042 & -0.0238 & 0.0192 \\
\hline OC151 & 1231 & 1 & 0 & 0.0010 & 0.0252 & -0.0213 \\
\hline
\end{tabular}


The results obtained by AIC are different a few centimeters from that ones by interactive mode generally, and are approximately similar to the results of Clark et al.(1985). But the differences will reach about 10 to 20 centimeters sometimes when the observations are more dispersive. It should not be negletcted in VLBI survey with so high accuracy.

By using AIC mode, the identification of clock models will base on a rigorous mathematical criterion and the effects on the results of VLBI from personal cause will essentially be elimited. Furthermore it will improve the efficiency of VLBI data processing because the clock model is automatically selected by computer.

\section{Acknowledgements:}

The work reported here was supported by a grant from the National Science Foundation as part of the Senior Visiting Scientist Program of the National Geodetic Survey Division, Charting and Geodetic Survices, National Oceanic and Atmospheric Administration.

\section{References:}

1.Akaike,H., (1973), Information theory and an extension of the maximum likelihood principle, 2nd Int.Symp. on Inf. Theory (B.N.Petry and F. Csaki),p267-281. Budapest: Akademiakiado.

2.Robertson,D,S., "Geodetic and astrometric measurments with very-long baseline interferometry", 1975, M.I.T. (Ph.D.Thesis)

3.Carter,W.E., D.S.Robertson and J.R.Mackay, "Geodetic radio interometric surveying: Applications and Results", J.Geophys.Res., 90, No.B6, p4577-4587,1985

4.Clark,T.A. C.Ma, J.W.Ryan and A.Mallama, A comparison of Earth Orientation Data obtaied by Different Space Techniques, Proceedings of International Conference on Earth Rotation and Terrestraal Reference Frame, Ohio, USA, (1985). 


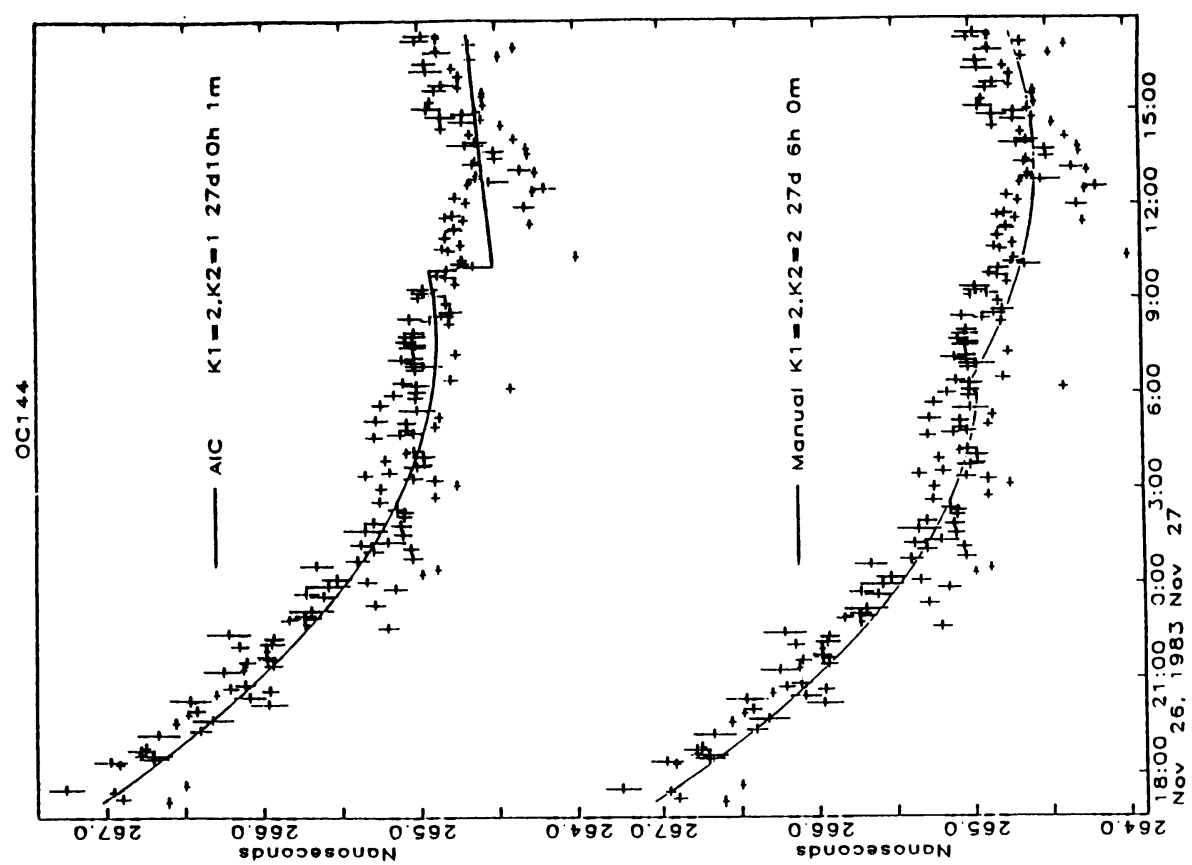

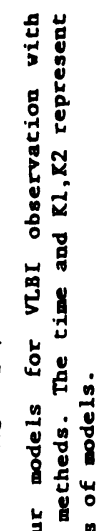

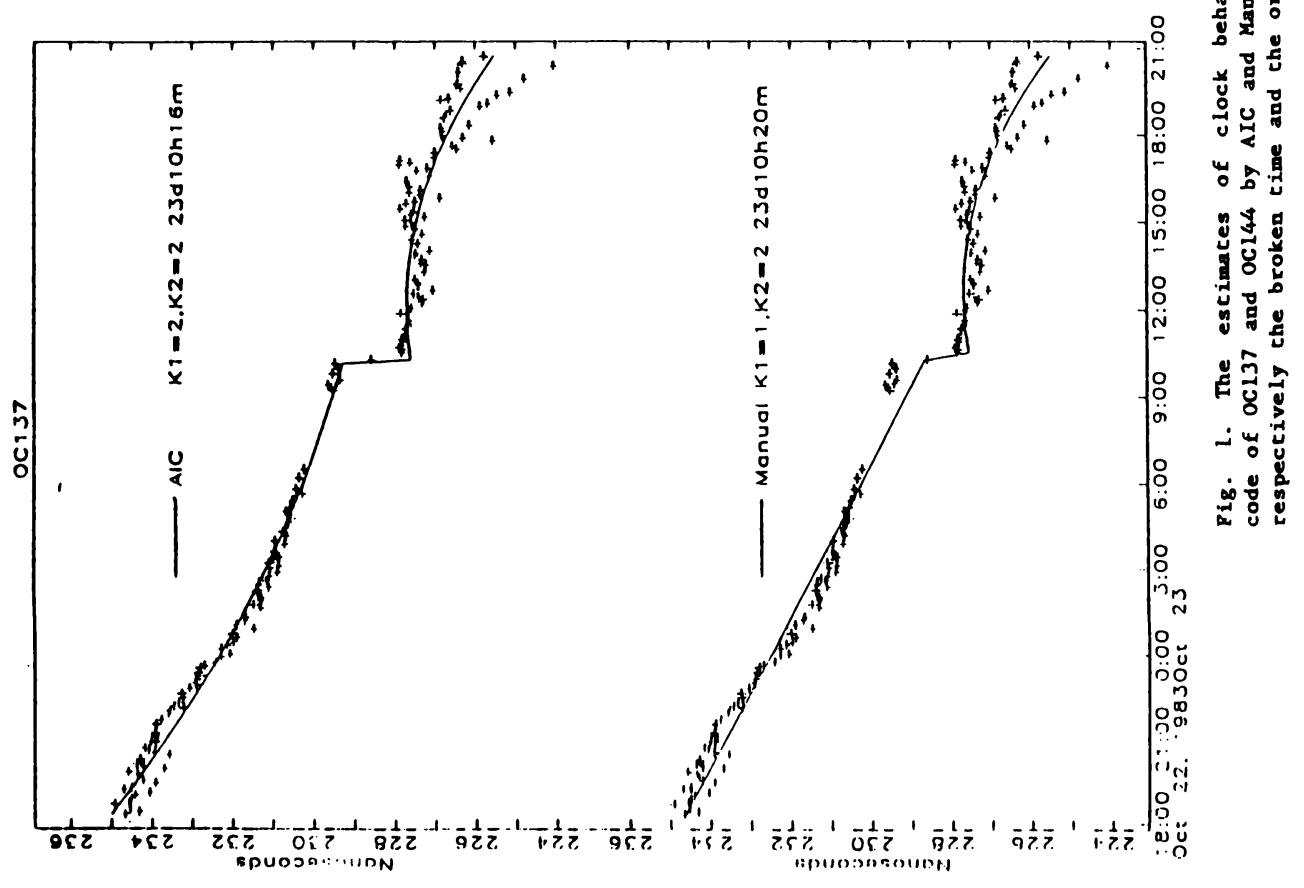

